\title{
PROTECTING COASTS AGAINST PROBABLE SEA LEVEL RISE USING POROUS VERTICAL SEAWALL *
}

\author{
El-Sadek M. Heikal , Ayman S. Koraim, Ahmed A. Abo Zaid** \\ Water and Water Structure Engineering Dept., Faculty of Engineering, Zagazig University, Egypt
}

\begin{abstract}
There are three main parameters affecting on seawall crest level determination: tidal range, wave run-up and sea level rising. In this paper, the hydrodynamic efficiency of a new type porous seawall is experimentally studied. This is by using physical models to minimize the run-up at the front of the wall. The seawall consists of front screen (steel screen suspended on nearly spaced piles), back solid wall and filled rock-core in between the two walls. The hydrodynamic efficiency of the seawall is presented as a function of the wave run-up, reflection, and energy dissipation coefficients. Different wave and structural parameters affecting the seawall efficiency are investigated. The results indicate that; the run-up and reflection coefficients decrease with increasing of relative wave length $(\mathrm{h} / \mathrm{L})$, wave steepness $\left(\mathrm{H}_{\mathrm{i}} / \mathrm{L}\right)$, relative porous media width $(\mathrm{B} / \mathrm{L})$ and porous media width-water depth ratio $(\mathrm{B} / \mathrm{h})$. The energy dissipation coefficient takes the opposite trend. The efficiency of the proposed porous seawall in reducing wave run-up and reflection coefficient is better than the impermeable type by about 10 to $25 \%$ and 20 to $40 \%$ respectively. In addition, it is better than the impermeable one in dissipating the incident wave energy by about 30 to $60 \%$. The increasing of the porous media width helps in reducing the wave run-up and reflection coefficient and increasing the dissipated wave energy by about 5 to $10 \%, 10$ to $20 \%$ and 5 to $20 \%$ respectively. The empirical equations are developed to estimate the run-up and reflection coefficients. The results of these equations compared with the experimental results and it give a reasonable agreement by about 80 to $90 \%$.
\end{abstract}

KEY WORDS: Seawalls, Porous structures; Wave Run-up; Reflection; Energy dissipation.

\section{PROTECTION DES CÔTES DE HAUSSE PROBABLE NIVEAU DE LA MER EN POREUX SEAWALL VERTICAL}

\begin{abstract}
RÉSUMÉ
Il existe trois principaux parametres qui affectent le niveau de determination digue de crete: niveau de l'amplitude des marees, des vagues run-up et des mers. Dans cet article, l'efficacite hydrodynamique d'une digue nouveau type poreux est etudiee experimentalement. C'est a l'aide de modeles physiques afin de minimiser la veille a l'avant du mur. La digue est constituee de l'ecran avant (ecran en acier suspendue sur pilotis pres espaces), mur arriere solide et remplie de roche-core entre les deux parois. L'efficacite hydrodynamique de la digue est presentee comme une fonction de l'onde run-up, la reflexion, et les coefficients de dissipation d'energie. D'onde differente et les parametres structurels qui affectent l'efficacite digue sont etudiees. Les resultats indiquent que, la veille et de reflexion coefficients diminuent avec l'augmentation de la longueur d'onde relative $(\mathrm{h} / \mathrm{l})$, cambrure (salut / 1), largeur relative des milieux poreux (b / 1) et poreux rapport des medias largeur profondeur d'eau (b/h). Le coefficient de dissipation de l'energie prend la tendance inverse. L'efficacite de la digue proposee poreuse dans la reduction des ondes run-up et le coefficient de reflexion est meilleur que le type impermeable d'environ 10 a $25 \%$ et de 20 a $40 \%$ respectivement. En outre, il est preferable que celui impermeable a dissiper l'energie onde incidente d'environ 30 a $60 \%$. L'augmentation de la largeur de support poreux permet de reduire l'onde de lancement et le coefficient de reflexion et augmenter l'energie dissipee onde d'environ 5 a $10 \%$, de 10 a $20 \%$ et de 5 a $20 \%$ respectivement. Les equations empiriques sont developpes pour estimer le run-up et des coefficients de reflexion. Les resultats de ces equations par rapport aux resultats experimentaux et de le donner a un accord raisonnable d'environ 80 a $90 \%$.
\end{abstract}

MOTS CLÉS: digues, les structures poreuses; vague run-up, reflexion, dissipation d'energie.

* $\quad$ Received: 20/3/2012, Accepted: 11/9/2012 (Original Paper)

** Contact author (abozeedahmed@yahoo.com, +2 01068067 674) 


\section{INTRODUCTION}

Seawalls are onshore structures with the principal function of preventing or alleviating overtopping and flooding of the land and the structures behind due to storm surges and waves. Seawalls are built parallel to the shoreline as a reinforcement of a part of the coastal profile. Quite often seawalls are used to protect promenades, roads, and houses placed seaward of the crest edge of the natural beach profile. In these cases a seawall structure protruding from the natural beach profile must be built. In addition, seawalls are consider good methods to control the probable sea level rising due to the climate changes. Seawalls range from vertical face structures such as massive gravity concrete walls, tied walls using steel or concrete piling, and stone-filled cribwork to sloping structures with typical surfaces being reinforced concrete slabs, concrete armor units, or stone rubble. When vertical, they are labeled non-energy absorbing, whereas if with a sloping surface or rubble mound, they absorb some energy. The front face may also be curved or stepped to deflect wave run-up.

The key functional element in seawall design is the crest elevation to minimize the overtopping from storm surge and wave runup. There are three main parameters affecting on seawall crest level: tidal range, wave run-up and sea level rising. The reflection and run-up characteristics of a seawall, in addition to its stability, are important parameters to be studied. The reflection from the vertical and slightly battered walls of impermeable type will be around 90 to $100 \%$. The reflection from these structures causes standing waves which are accompanied by increased water particle velocities, leading to more erosion along the face of the wall and may lead to undermining the structure (Mallayachari and Sundar 1994).

The construction of sloping rubble mound walls will reduce the level of reflections to limit the problem of local scour when waves approach normal to the shore. These structures require large quantity of stones especially when the water depth and wave height increase. And to avoid this point, the vertical porous seawall can be used instead of the sloped one. The simplest form of the vertical porous seawall is rock-filled work. In which the seawall consists of front screen (steel screen suspended on nearly spaced piles), back solid wall and filled rock-core in between the two walls.

The present investigation with porous, vertical seawall has been carried out with the following objectives:

1.To propose a new type seawall helping in crest level reduction by dissipating the most of incident wave energy.

2. To investigate experimentally the wave runup, reflection and energy dissipation characteristics of the proposed seawall.

3. To investigate the same characteristics for different wave climate and structure configurations.

\section{PREVIOUS WORK}

In recent decades, with porous structures being widely used in coastal areas, the phenomena of wave interaction with these structures have been studied theoretically and experimentally by many investigators. Straub et al 1957 reported the reflection characteristics of permeable wave absorbers of different porosities, lengths and configurations through an experimental program. Lean 1967 proposed a simplified analytical model for the evaluation of reflection characteristics of permeable wave absorbers due to long waves. Sollitt and Cross 1972 presented a summary of previous analytical approaches to the problem of predicting the transmission and the reflection characteristics of a porous structure. Madsen 1974 produced a simple solution for the reflection and the transmission coefficients based on the assumption of relative long normally incident waves on a rectangular homogeneous porous structure. Madsen 1983 presented a theoretical solution for the reflection of linear shallow water waves from a vertical homogeneous wave absorber on a horizontal bottom. Sulisz 1985 formulated a theory to predict the wave reflection and transmission at an infinite rubble mound breakwater under normal wave incidence.

Dalrymple et al 1991 adopted the Sollit and Cross 1972 approach to analyze the reflection and transmission of oblique incident waves from infinitely long porous structures. 
Huang and Chao 1992 investigated a smallamplitude water wave acting on a vertical porous breakwater in an infinitely long channel. Losada et al 1993 extended this study to the case of an infinitely long, homogenous, vertical structure capped with an impervious element under oblique wave incidence. Mallayachari and Sundar 1994 determined the reflection characteristics of permeable vertical seawalls with a numerical model which based on Green's Identity formula. The variation of the reflection coefficients with the porosity of the wall, its friction factor and the relative wall width was studied. Yu 1995 presented a solution of the two-dimensional problem of wave reflection and transmission by a permeable vertical barrier. Liu et al 1999 presented a numerical model for simulating wave interaction with porous structures. The model calculates the mean flow outside of porous structures based on the Reynolds averaged Navier-Stokes equations.

Recently, Isaacson et al 2000 presented a theoretical analysis and an associated numerical model used to assess the performance of a breakwater consisting of a perforated front wall, an impermeable back wall, and a rock-filled core. The numerical method was based on an Eigenfunction Expansion and utilizes a boundary condition at the perforated wall that accounts for energy dissipation. Requejo et al 2002 proposed a mathematical model to solve the potential flow around and inside a porous breakwater. The reflection, transmission, dissipation, horizontal and vertical forces and overturning moment were solved. Twu and Liu 2004 developed a computational model to investigate the wave damping characteristics of a periodic array of porous bars. The transmission and reflection coefficients as well as the wave energy dissipation were evaluated relating to the physical properties and geometric factors of bars. Hsu et al 2005 derived an analytical solution of oblique water waves impacting on thin porous walls based on the concept that the wave direction remains unchanged as it permeates into the thin porous medium.

Lin and Karunarathna 2007 studied the solitary wave interaction with porous breakwaters by using a two-dimensional numerical model. The flows outside of porous media were described by Reynolds-averaged
Navier-Stokes equations. Rageh 2009 experimentally studied the efficiency of the vertical thick submerged or emerged porous structures under normal and regular waves with wide ranges of wave heights and periods. Theocharis et al 2011 investigated experimentally a new type of wave absorbing quay-wall with a partial wave chamber containing a rock-armored slope. In addition to the basic design containing a wave chamber with an impermeable back wall, there were several alternative absorbing systems that use rock within the core of the wave chamber.

The detailed literature review reveals that there are some references available on similar models. There are little works, in particular experimental investigations, carried out for studying the vertical porous seawalls. So that, the efficiency of the vertical porous seawall that consists of front screen, back solid wall and crushed stone filled in between the two walls is experimentally studied using physical model. The seawall efficiency is presented as a function of run-up, reflection, and wave energy dissipation coefficients. The effect of different wave and structural parameters on the seawall efficiency is investigated such as; the incident wave length and height and the seawall permeability and width.

\section{EXPERIMENTAL WORK}

Several experiments are carried out in a wave flume $13.0 \mathrm{~m}$ long, $0.45 \mathrm{~m}$ deep, and $0.30 \mathrm{~m}$ wide in the Hydraulics and Water Engineering Laboratory of the Faculty of Engineering, Zagazig University, Zagazig, Egypt. Its vertical sides are made from toughened glass of $0.012 \mathrm{~m}$ thickness. A flap type wave generator with stroke distance of $0.22 \mathrm{~m}$ is installed at one end of the flume. This wave generator is used to generate regular wave trains with different wave periods. A steel screen wave absorber with slope 3:1 is installed at the other end of the flume to absorb the transmitted waves. Froude scaling technique is adopted for physical modeling, which allows for the correct reproduction of gravitational and fluid inertial forces. A scale of 1:20 is chosen for the selection of model dimensions and wave properties in the present study. 
PROTECTING COASTS AGAINST PROBABLE SEA LEVEL RISE USING POROUS VERTICAL SEAWALL

Heikal, Koraim, Abo Zaid

The tested seawall model is placed at the end of the wave flume. Two seawall models are tested. The first model is graffito impermeable wall with thickness of $0.02 \mathrm{~m}$. The second model is porous seawall consists of front screen wall, back solid wall and corerock filled in between the two walls with width $\mathrm{B}=0.125,0.25$ and $0.375 \mathrm{~m}$. The height of the core-rock is enough to prevent the wave overtopping on the seawall. Details of the tested models and experimental setup ranges are shown in Fig. 1 and Table 1. Also, the component of the tested model and the general view of the tested model are presented in Figures 2 and 3. in addition, the results of the sieve analysis of the core-rock is shown in Fig. 4.

\begin{tabular}{|c|c|c|}
\hline Parameter & Units & Ranges \\
\hline Water depth (h) & $\mathbf{m}$ & 0.20 and 0.25 \\
\hline Wave periods (T) & $\mathbf{S}$ & 0.65 to 1.90 \\
\hline Wave length $(\mathrm{L})$ & $\overline{\mathbf{m}}$ & 0.67 to 2.90 \\
\hline Seawall width (B) & $\mathbf{m}$ & $0.125,0.25$ and 0.375 \\
\hline Rock mean diameter $\left(d_{50}\right)$ & $\mathbf{m}$ & 0.017 \\
\hline Rock porosity (n) & - & $45 \%$ \\
\hline Rock weight (w) & $\mathbf{t}$ & $(11-18) \times 10^{-6}$ \\
\hline Relative wave length $(\mathrm{h} / \mathrm{L})$ & - & $0.08-0.37$ \\
\hline Wave steepness $\left(\mathrm{H}_{\mathrm{i}} / \mathrm{L}\right)$ & - & $0.018-0.095$ \\
\hline Relative seawall width(B/L) & - & $0.045-0.863$ \\
\hline Width-depth ratio (B/h) & - & 0.5-1.875 \\
\hline
\end{tabular}

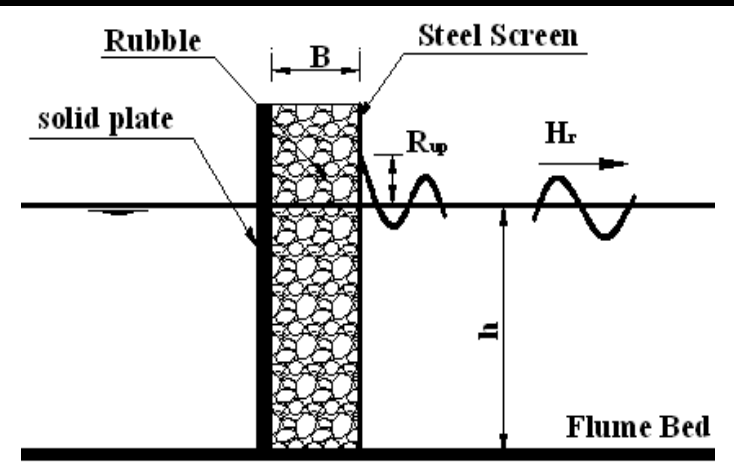

Fig. 1. Details of the tested seawall mod

Table 1. Experimental setup parameters for the proposed seawall model.

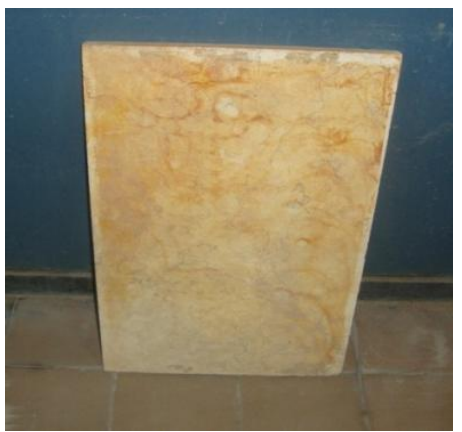

(a) The used rock.

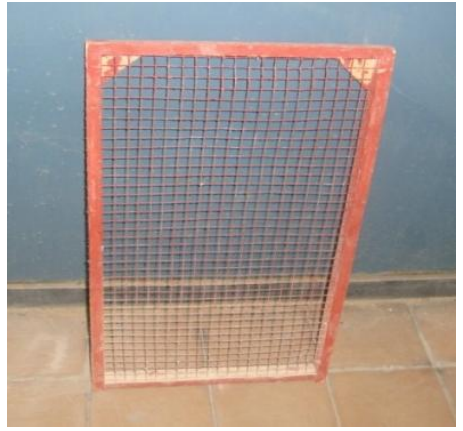

(b) The steel screen

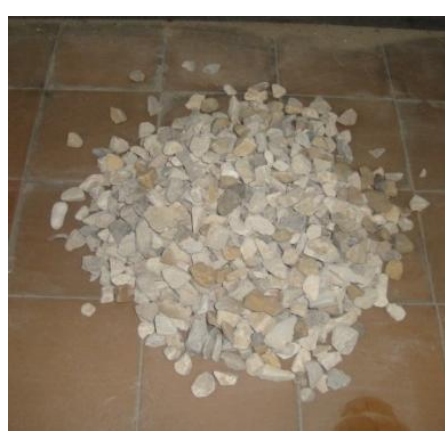

(c) The solid back wall

Fig. 2. General view of different components of the tested seawall model

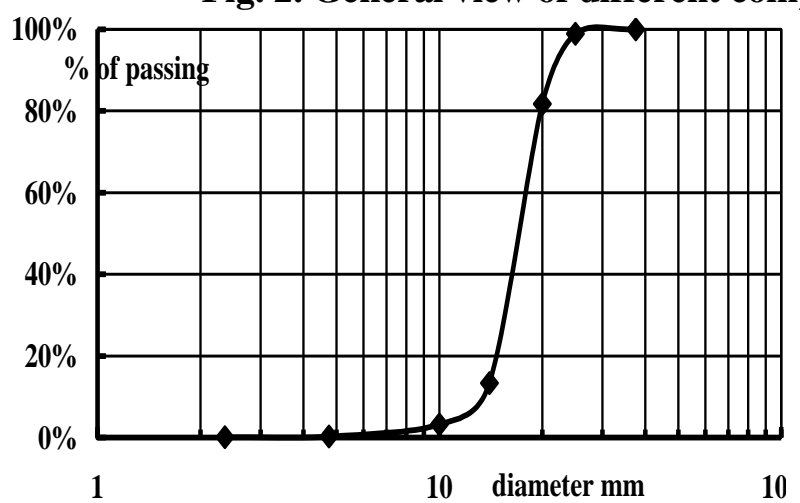

Fig. 3. Sieve analysis for the used rock.

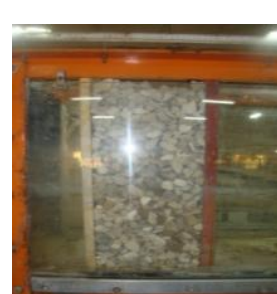

(a) Elevation

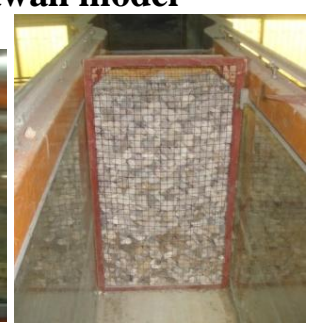

(b) Side view

Fig. 4. General view of the tested seawall model.

Standard conductivity type wave probe is used to measure the wave elevations. The wave probe comprises of two thin parallel stainless steel electrodes. The probe consists of two $0.0015 \mathrm{~m}$ diameter stainless steel wires spaced $0.0125 \mathrm{~m}$ apart 
and $0.30 \mathrm{~m}$ long. The probe is connected to wave monitor module in the electronic console by a twin core flexible cable. This monitor provides output signals in form of voltage data. Static calibration of the wave probe is carried out every day and at the beginning and end of each set of experiments. The calibration constants are found to have a standard deviation of less than $1.0 \%$. An electronic converter has been used for converting analogue signals to digital voltage data. These data are collected by the personal computer and converted to the wave elevation by simple computer program. Then the variation of water surface with time can be drawn. To measure the incident $\left(\mathrm{H}_{\mathrm{i}}\right)$ and reflected $\left(\mathrm{H}_{\mathrm{r}}\right)$ wave heights, two recording positions $\mathrm{P}_{3}$ and $\mathrm{P}_{2}$ $\left(\mathrm{H}_{\text {max. }}\right.$ at location $\mathrm{P}_{3}$, the quasi-antinodes, and $\mathrm{H}_{\text {min. }}$. at location $\mathrm{P}_{2}$, the quasi-nodes) are located in front of the seawall model (wave generator side). The positions $\mathrm{P}_{3}$ and $\mathrm{P}_{2}$ located at distances $\mathrm{L}$ and 1.25 $\mathrm{L}$ ( $\mathrm{L}$ is the wave length and it is variable according to the wave period $\mathrm{T}$ ) from the model face according to Dean and Dalrymple 1984. The incident $\left(\mathrm{H}_{\mathrm{i}}\right)$ and the reflected $\left(\mathrm{H}_{\mathrm{r}}\right)$ wave heights estimated by:

$\mathrm{H}_{\mathrm{i}}=\left(\mathrm{H}_{\max .}+\mathrm{H}_{\text {min. }}\right) / 2$

$\mathrm{H}_{\mathrm{r}}=\left(\mathrm{H}_{\text {max. }}-\mathrm{H}_{\text {min. }}\right) / 2$

To measure the wave run-up $\left(\mathrm{R}_{\mathrm{up}}\right)$, one additional recording position $\left(\mathrm{P}_{4}\right)$ is set at the front of the seawall. In addition, the recording position $\left(\mathrm{P}_{1}\right)$ is located at distance of $2.0 \mathrm{~m}$ from the wave generator for measuring the incident wave height to inshore the calculated one from Eq. (1). Details of wave flume, position of the tested seawall models, and locations of wave recording are shown in Fig. 5. The run-up $\left(\mathrm{k}_{\mathrm{rp}}\right)$ and reflection $\left(\mathrm{k}_{\mathrm{r}}\right)$ coefficients can be estimated by:

$\mathrm{k}_{\mathrm{rp}}=\mathrm{R}_{\mathrm{up}} / \mathrm{H}_{\mathrm{i}}$

$\mathrm{k}_{\mathrm{r}}=\mathrm{H}_{\mathrm{r}} / \mathrm{H}_{\mathrm{i}}$

The energy equilibrium of an incident wave attack the structure can be expressed as follows:

$\mathrm{E}_{\mathrm{i}}=\mathrm{E}_{\mathrm{r}}+\mathrm{E}_{\mathrm{d}}$

In which, $E_{i}$ is the energy of incident wave $\left(\mathrm{E}_{\mathrm{i}}=\rho g \mathrm{H}_{\mathrm{i}}{ }^{2} / 8, \rho\right.$ is the water density and $\mathrm{g}$ is the acceleration of gravity), $\mathrm{E}_{\mathrm{r}}$ is the energy of reflected wave $\left(E_{r}=\rho g H_{r}^{2} / 8\right)$, and $E_{d}$ is the wave energy dissipation. Substituting in Eq. (5) by values of $E_{i}$ and $E_{r}$ and dividing by $E_{i}$, yields:

$1=\frac{\mathrm{H}_{\mathrm{r}}^{2}}{\mathrm{H}_{\mathrm{i}}^{2}}+\frac{\mathrm{E}_{\mathrm{d}}}{\mathrm{E}_{\mathrm{i}}}$

Substituting by Eqs. (4) in Eq. (6), the wave energy dissipation coefficient $\mathrm{k}_{\mathrm{d}}=\left(\mathrm{E}_{\mathrm{d}} / \mathrm{E}_{\mathrm{i}}\right)^{1 / 2}$ can be estimated as follows:

$$
\mathrm{k}_{\mathrm{d}}=\sqrt{1-\mathrm{k}_{\mathrm{r}}^{2}}
$$

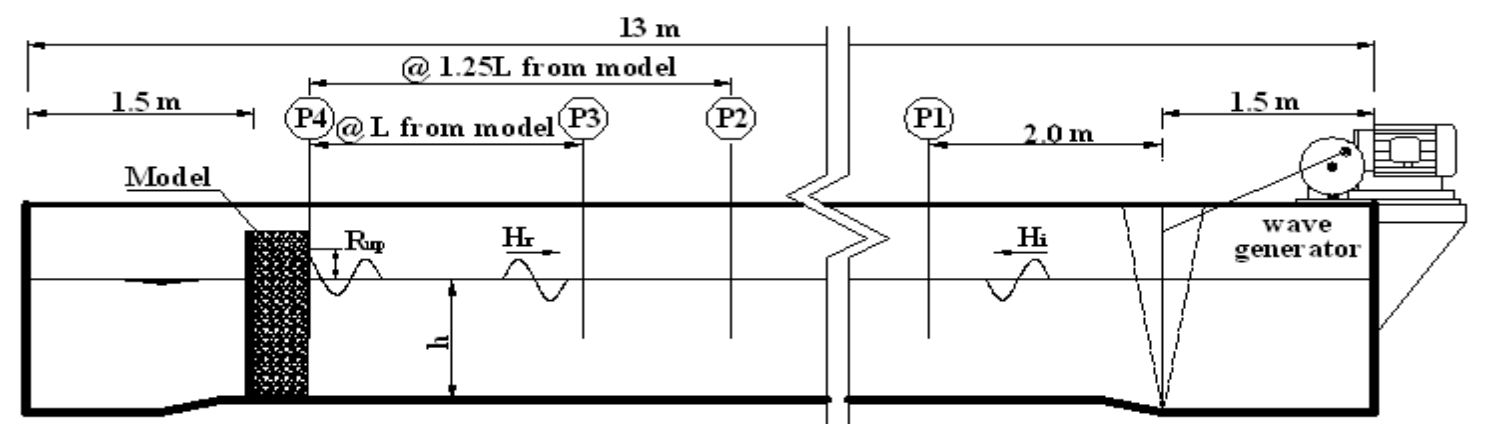

Fig. 5. Details of wave flume, position of model and location of wave recordings.

\section{RESULTS AND ANALYSIS}

\subsection{Dimensional Analysis}

Many parameters affecting the seawall efficiency are studied such as incident wave length and height (L, Hi), water depth (h), seawall porosity and width (n, B). The analysis presents the efficiency of the seawall in the form of relationships between run-up, reflection, and energy dissipation coefficients 
(Rup/Hi, kr, kd) and dimensionless parameters representing the wave and structure characteristics as following:

$\mathrm{R}_{\text {up }} / \mathrm{H}_{\mathrm{i}}, \mathrm{k}_{\mathrm{r}}, \mathrm{k}_{\mathrm{d}}=f\left(\mathrm{~h} / \mathrm{L}, \mathrm{H}_{\mathrm{i}} / \mathrm{L}, \mathrm{B} / \mathrm{L}, \mathrm{B} / \mathrm{h}, \mathrm{n}\right)$

Investigating the effect of $\mathrm{h} / \mathrm{L}$ and $\mathrm{Hi} / \mathrm{L}$ on

$\mathrm{Rup} / \mathrm{Hi}, \mathrm{kr}$ and $\mathrm{kd}$ is essential to understand the hydrodynamic characteristics of the present seawall for coastal regions. Also, to understand the performance of the seawall for normal and extreme wave actions. In addition, investigating the effect of $\mathrm{B} / \mathrm{h}, \mathrm{B} / \mathrm{L}$, and $\mathrm{n}$ on $\mathrm{Rup} / \mathrm{Hi}, \mathrm{kr}$ and $\mathrm{kd}$ is required to select the appropriate structure configuration.

Using the above dimensionless parameters [Eq.(8)], the Regression analysis and $75 \%$ of the measured data, two simple empirical equations to estimate the run-up and reflection coefficients are developed as follows:

For impermeable case $(\mathrm{n}=0)$

$$
\begin{aligned}
& \mathrm{R}_{\mathrm{up}} / \mathrm{H}_{\mathrm{i}}=1.06(\mathrm{~h} / \mathrm{L})^{-0.28}\left(\mathrm{H}_{\mathrm{i}} / \mathrm{L}\right)^{0.13}, \\
& \mathrm{R}^{2}=0.80 \\
& \mathrm{k}_{\mathrm{r}}=0.98(\mathrm{~h} / \mathrm{L})^{-0.08}\left(\mathrm{H}_{\mathrm{i}} / \mathrm{L}\right)^{0.07}, \\
& \mathrm{R}^{2}=0.85
\end{aligned}
$$

For porous case $(\mathrm{n}=45 \%)$

$$
\begin{aligned}
& \mathrm{R}_{\mathrm{up}} / \mathrm{H}_{\mathrm{i}}=0.78(\mathrm{~h} / \mathrm{L})^{0.36}\left(\mathrm{H}_{\mathrm{i}} / \mathrm{L}\right)^{0.44}(\mathrm{~B} / \mathrm{L})^{-0.56} \\
& (\mathrm{~B} / \mathrm{h})^{-0.03}, \mathrm{R}^{2}=0.83 \\
& \mathrm{k}_{\mathrm{r}}=0.40 \quad(\mathrm{~h} / \mathrm{L})^{-1.95}\left(\mathrm{H}_{\mathrm{i}} / \mathrm{L}\right)^{1.79}(\mathrm{~B} / \mathrm{L})^{1.94} \\
& (\mathrm{~B} / \mathrm{h})^{-0.13}, \mathrm{R}^{2}=0.88
\end{aligned}
$$

Then the wave energy dissipation coefficients $\mathrm{k}_{\mathrm{d}}$ can be estimated from Eq. (7). The above equations are applicable for ranges shown in Table 1.

\subsection{Experimental Measurements Analysis}

Figures 6 and 7 show a sample of the analyzed data using the wave probe at the four wave recording positions $\mathrm{P} 1, \mathrm{P} 2, \mathrm{P} 3$ and $\mathrm{P} 4$ for the case of porous seawall and $\mathrm{h}=0.20 \mathrm{~m}$, $\mathrm{B}=0.25 \mathrm{~m}$ when $\mathrm{T}=0.68$ and $1.8 \mathrm{~s}$ respectively. Figures $6 \mathrm{a}$ and $7 \mathrm{a}$ show that the first 2 to $5 \mathrm{~s}$, the wave travels from the wave generator to

the wave gauge at location P1. Some disturbance appears in the shape of the wave for few seconds then, the wave seems to be very stable for some time ( $t=5$ to $15 \mathrm{~s}$ ) which is the suitable period to measure the incident wave height. After this time, the reflected waves from the seawall model affecting on the incident waves.
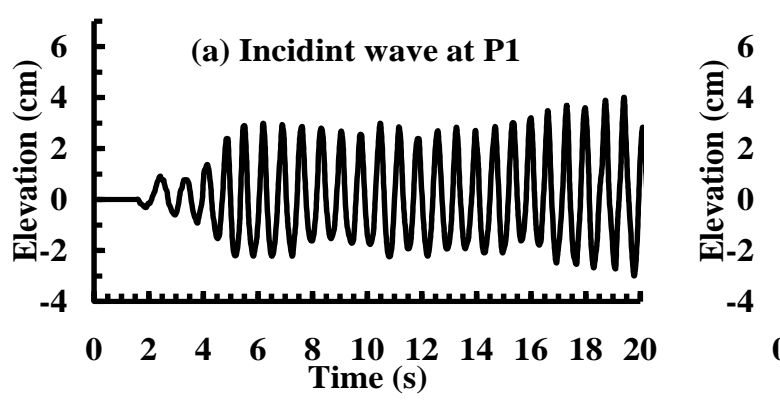

(a)
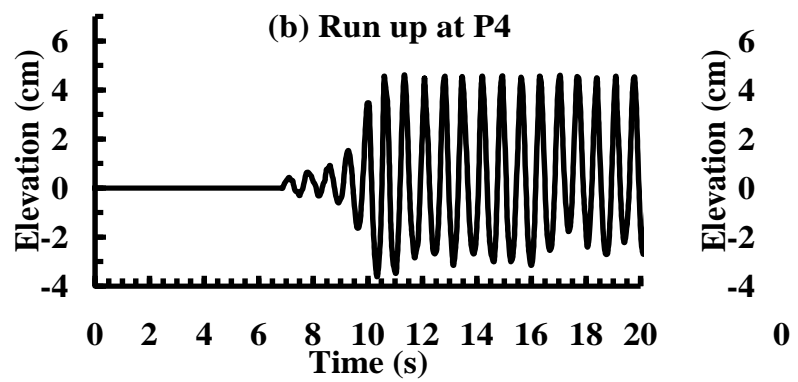

(b) Run
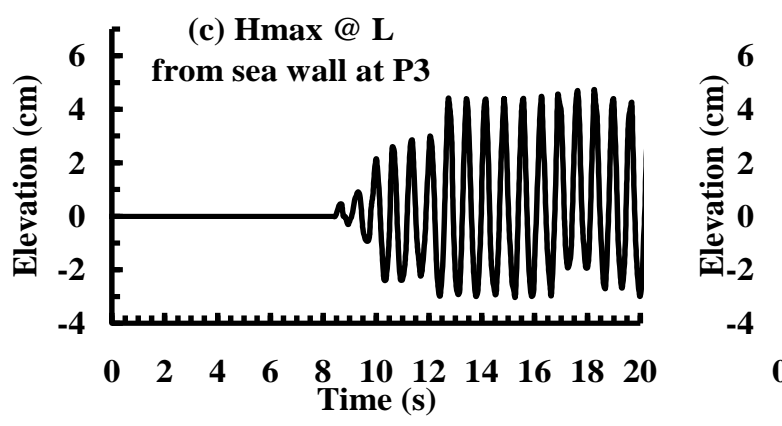

(c) $\mathrm{H}$

from se

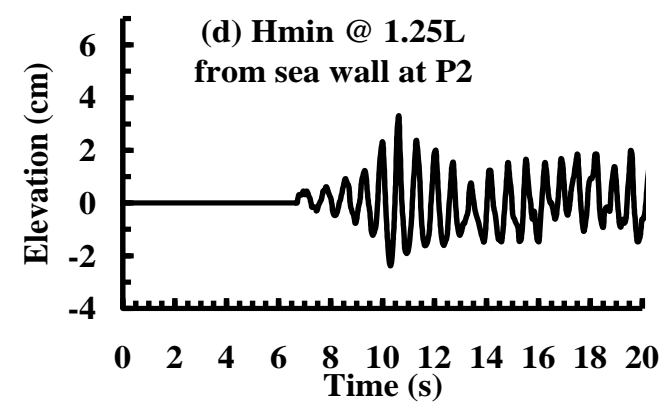

Fig. 6. Variation of wave elevation with time at the different wave recording positions for the case of porous seawall when $h=0.20 \mathrm{~m}, B=0.25 \mathrm{~m}$, and $T=0.68 \mathrm{~s}$. 

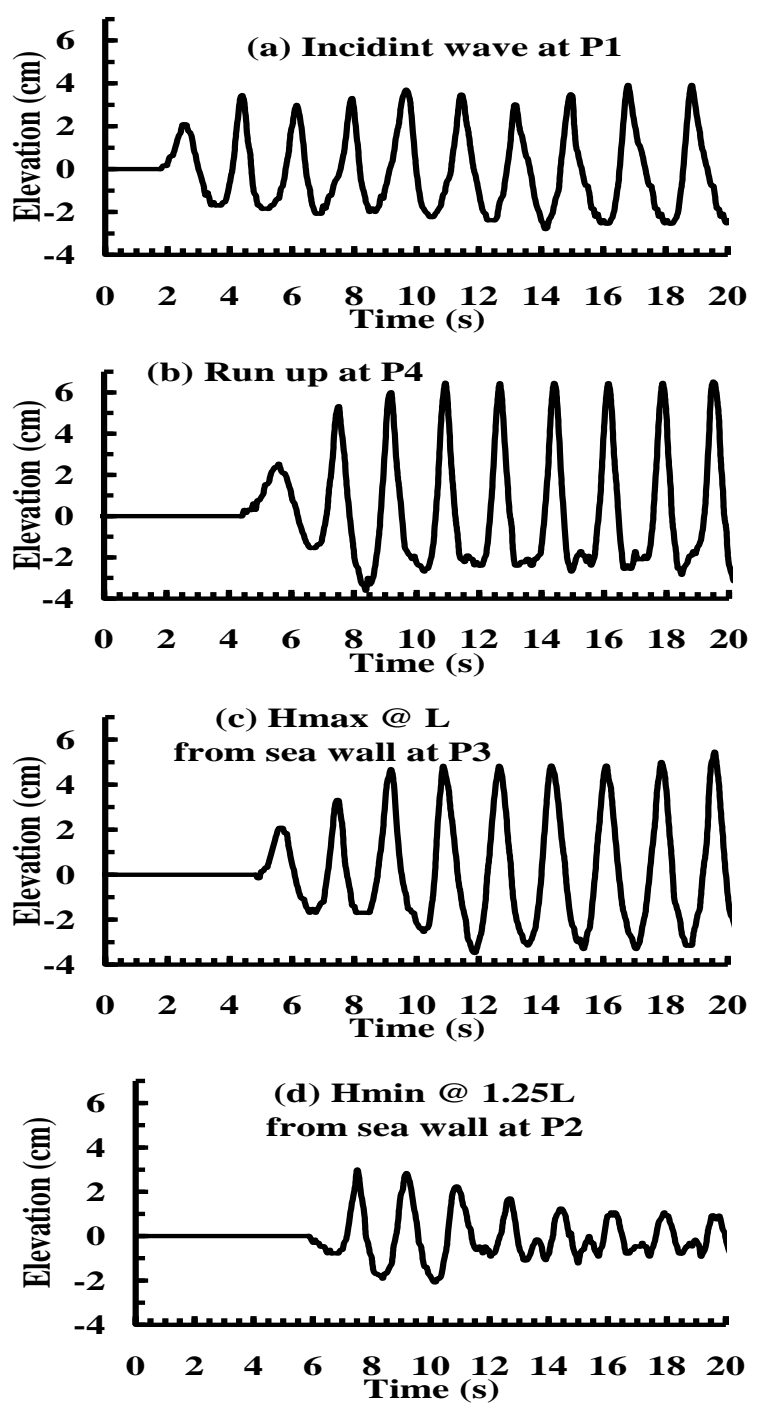

Fig. 7. Variation of wave elevation with time at the different wave recording positions for the case of porous seawall when $h=0.20 \mathrm{~m}, B=0.25 \mathrm{~m}$, and $\mathbf{T}=1.8 \mathrm{~s}$

Figures $6 \mathrm{~b}, \mathrm{c}, \mathrm{d}$ and $7 \mathrm{~b}, \mathrm{c}, \mathrm{d}$ show that the first 8 to $12 \mathrm{~s}$, the wave travels from the wave generator to the wave gauges at location P2, P3, P4 and reflects from the seawall model and the partial standing wave begins to build its shape. After that, the wave tends to be stable for some time ( $\mathrm{t}=10$ to $15 \mathrm{~s}$ ) which is the period of the suitable zone to estimate the run-up and reflection coefficients. After this time, the form of the partial standing wave changes due to the new reflection of the wave from the wave generator, which generates a new incident wave with different characteristics. The reflection coefficients are estimated from the data obtained by wave gauge at locations P2 and P3 while the run-up coefficients are estimated from the data obtained by wave gauge at location P4. In addition, the figures show that, the wave of $\mathrm{T}=1.9 \mathrm{~s}$ seems not uniform than the wave of $\mathrm{T}=0.68 \mathrm{~s}$. This is attributed to the effect of the shoaling on the wave profile in which the wave of $T=1.9 \mathrm{~s}$ is longer than the wave of $\mathrm{T}=0.68 \mathrm{~s}$.

\subsection{Empirical Equations Verification}

Figures 8 and 9 present the comparison between the measured and calculated run-up and reflection coefficients for solid and porous cases respectively. It can be observed from the figures that a good agreement is obtained between the experimental and the calculated hydrodynamic coefficients. The equations somewhat over-predict and under-predict the hydrodynamic coefficients by values not more than $10 \%$. The scatter between the experimental and calculated reflection coefficients is almost smaller than the scatter in run-up coefficients. In which the coefficient of determination R2 (determined from the regression analysis) for run-up (R2=0.83 and $0.85)$ is smaller than for the reflection ( $R 2=0.88$ and 0.91). This is may be due to the

high turbulence caused by the multiple wave reflections between the seawall and the wave generator.

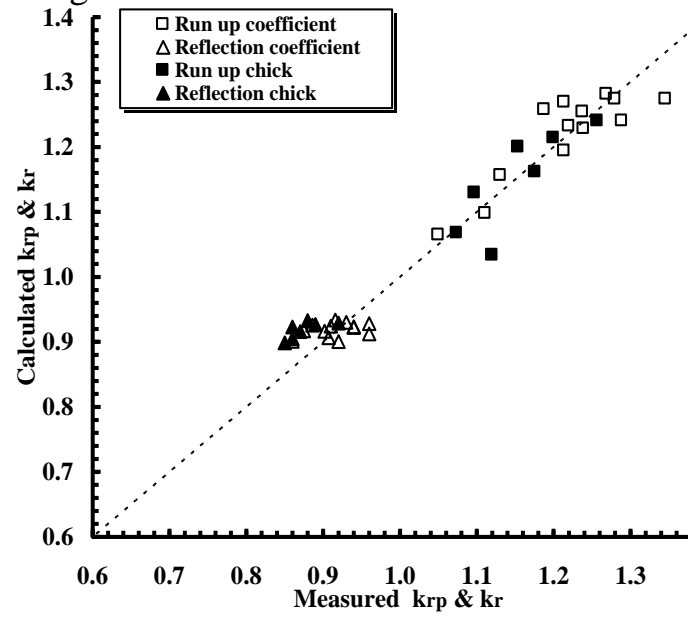

Fig. 8. Comparison between measured and calculated hydrodynamic coefficients for solid seawall. 


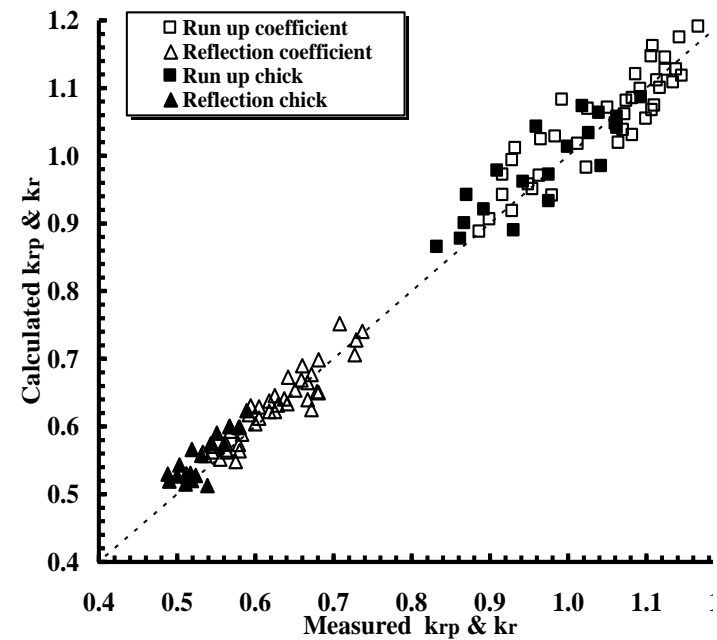

Fig. 9. Comparison between measured and calculated hydrodynamic coefficients for porous seawall.

\subsection{Experimental Results Analysis}

Fig. 10 presents the relationship between the calculated and measured different hydrodynamic coefficients and the relative wave length $(h / L=0.08-0.37)$ for different structural parameters (impermeable and porous cases). The figure presents the effect of the relative wave length $(\mathrm{h} / \mathrm{L})$, the seawall porosity and the porous seawall width-water depth ratio $(\mathrm{B} / \mathrm{h})$ on the seawall hydrodynamic efficiency. The figure shows that, all calculated and measured run-up (Rup/Hi) and reflection (kr) coefficients decrease with increasing values of $\mathrm{h} / \mathrm{L}$ for all cases while the dissipation coefficient (kd) takes the opposite trend e.g., calculated Rup/Hi and kr decrease from 1.27 to 1.05 and from 0.92 to 0.86 and calculated $\mathrm{kd}$ increases from 0.4 to 0.5 with $\mathrm{h} / \mathrm{L}$ increasing from 0.09 to 0.36 for the solid case. This can be explained by considering the water particle motions. When the wave strikes the model, the water particle velocity and acceleration suddenly change and the turbulence caused due to this sudden change in the particle motion causes the dissipation of wave energy.

The figure shows also, all Rup/Hi and kr caused by the porous model are smaller than those caused by solid model while kd follows the opposite trend e.g. calculated Rup/Hi and $\mathrm{kr}$ decrease from 1.16 to 1.04 and from 0.89 to 0.62 and calculated $\mathrm{kd}$ increases from 0.45 to 0.78 when the porous model of $\mathrm{B} / \mathrm{h}=0.5$ instead of solid model for $\mathrm{h} / \mathrm{L}=0.2$.
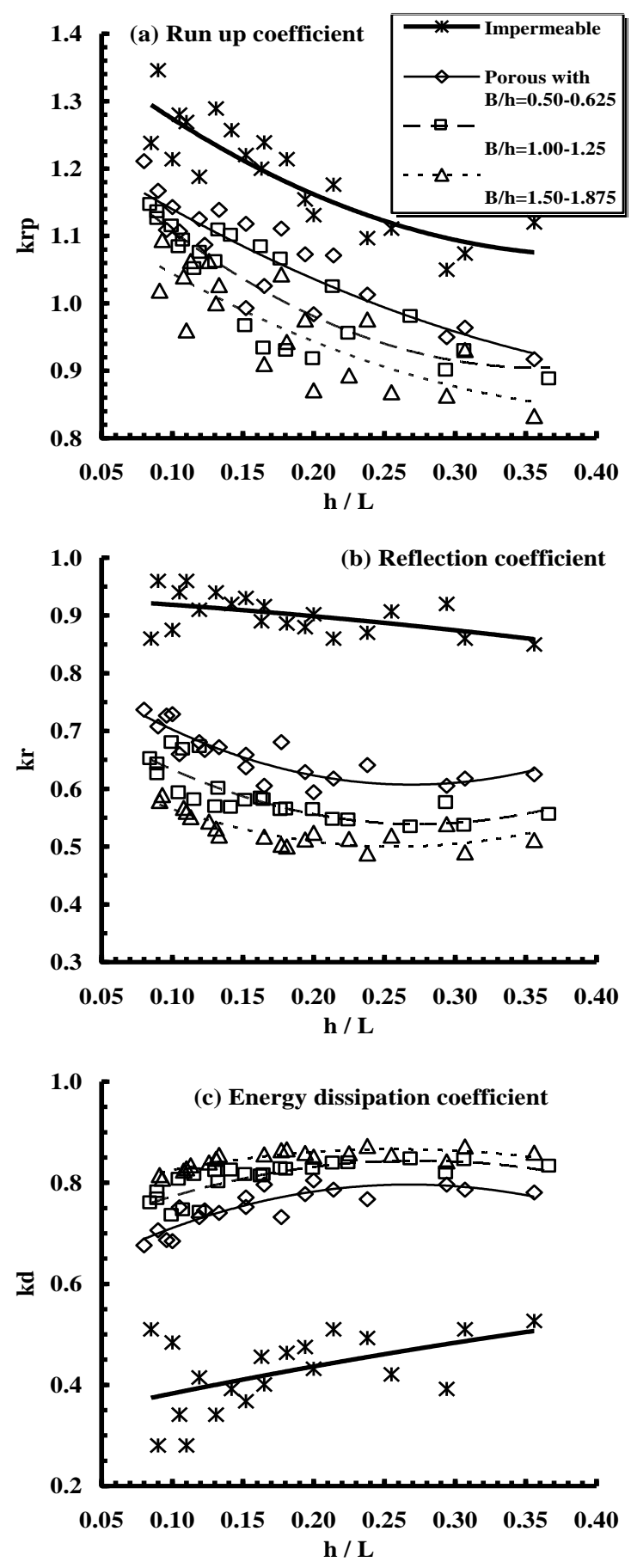

Fig. 10. Effect of $h / L$ and $B / h$ on the different hydrodynamic coefficients.

This is due to the dissipated wave energy through the porous media of the seawall and then the reflected waves decrease. The figure shows also, when $\mathrm{B} / \mathrm{h}$ increases $\mathrm{Rup} / \mathrm{Hi}$ and $\mathrm{kr}$ decrease and $\mathrm{kd}$ increases e.g. calculated Rup/Hi and kr decrease from 1.04 to 0.93 and from 0.62 to 0.51 and calculated $\mathrm{kd}$ increases from 0.78 to 0.86 when $\mathrm{B} / \mathrm{h}$ increases from 
$\mathrm{B} / \mathrm{h}=0.5$ to 1.5 for $\mathrm{h} / \mathrm{L}=0.2$. This can be attributed to the increase of the friction between the seawall porous media and the waves. As $\mathrm{B} / \mathrm{h}$ increases, the width of the porous media that becomes subjected to the waves increases. Then the friction length increases causing more wave energy dissipation. In addition, the figure shows that, a reasonable agreement is obtained between the calculated and the measured hydrodynamic coefficients.
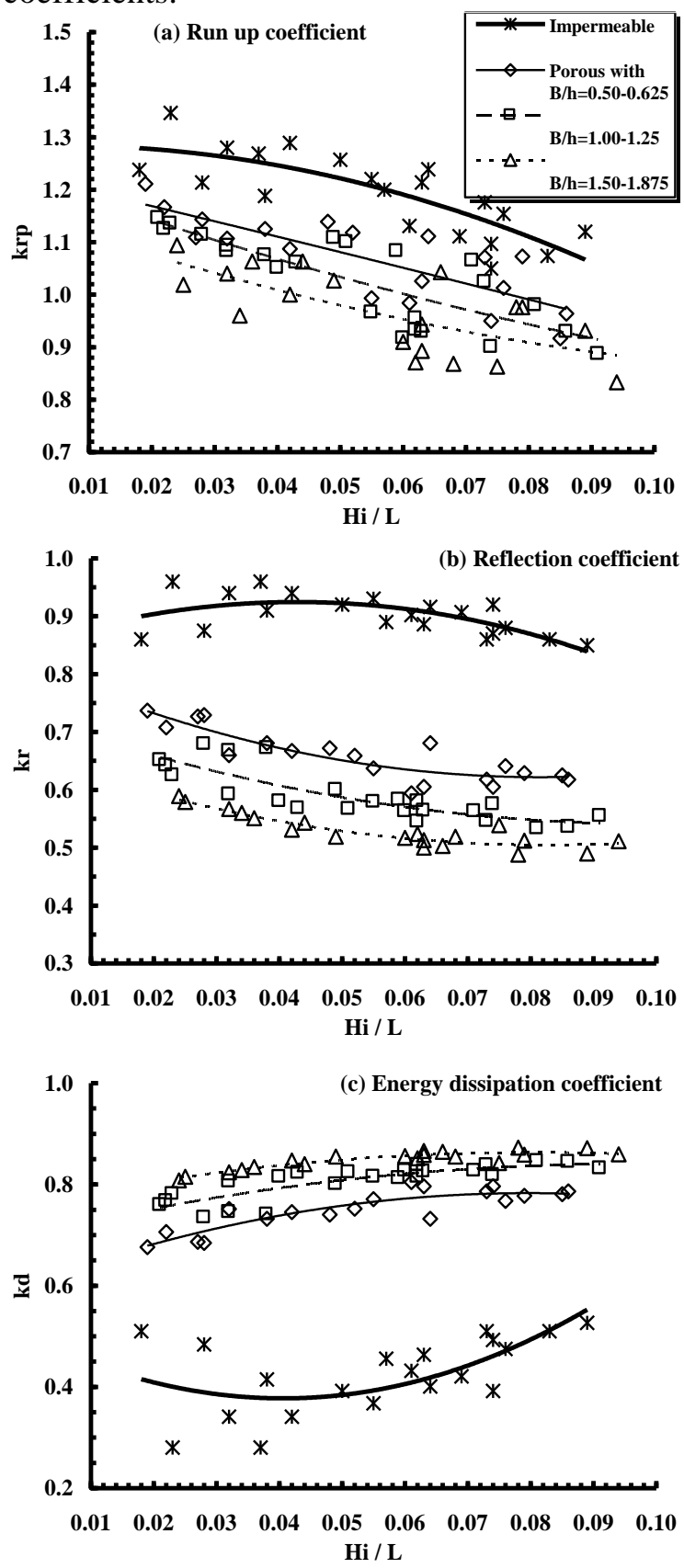

Fig. 11. Effect of $H_{i} / L$ and $B / h$ on the different hydrodynamic coefficients.
Fig. 11 illustrates the effect of the wave steepness $(\mathrm{Hi} / \mathrm{L})$, porosity and $\mathrm{B} / \mathrm{h}$ on the measured and calculated seawall hydrodynamic efficiency. The figure shows that, all Rup/Hi and $\mathrm{kr}$ decrease and all $\mathrm{kd}$ increase with $\mathrm{Hi} / \mathrm{L}$ increasing e.g. calculated Rup/Hi and kr decrease from 1.27 to 1.05 and from 0.92 to 0.86 and calculated $\mathrm{kd}$ increases from 0.4 to 0.5 with $\mathrm{Hi} / \mathrm{L}$ increasing from 0.018 to 0.09 for the solid case. Also, all $\mathrm{Rup} / \mathrm{Hi}$ and $\mathrm{kr}$ caused by the porous model are smaller than those caused by solid model while $\mathrm{kd}$ follows the opposite trend e.g. calculated Rup/Hi and kr decrease from 1.23 to 1.09 and from 0.91 to 0.65 and calculated $\mathrm{kd}$ increases from 0.41 to 0.76 when the porous model of $\mathrm{B} / \mathrm{h}=0.5$ instead of solid model for $\mathrm{Hi} / \mathrm{L}=0.05$. In addition, when $\mathrm{B} / \mathrm{h}$ increases $\mathrm{Rup} / \mathrm{Hi}$ and $\mathrm{kr}$ decrease and $\mathrm{kd}$ increases e.g. calculated Rup/Hi and kr decrease from 1.09 to 1.01 and from 0.65 to 0.54 and calculated $\mathrm{kd}$ increases from 0.76 to 0.84 when $\mathrm{B} / \mathrm{h}$ increases from $\mathrm{B} / \mathrm{h}=0.5$ to 1.5 for $\mathrm{Hi} / \mathrm{L}=0.05$. In addition, the figure shows that, a reasonable agreement is obtained between the calculated and the measured hydrodynamic coefficients.

Fig. 12 shows the effect of the relative porous seawall width $(\mathrm{B} / \mathrm{L})$ on the measured and calculated $\mathrm{Rup} / \mathrm{Hi}$, $\mathrm{kr}$ and $\mathrm{kd}$. The figure shows that, all Rup/Hi and $\mathrm{kr}$ decrease with $\mathrm{B} / \mathrm{L}$ increasing and $\mathrm{kd}$ takes the opposite trend e.g. calculated $\mathrm{Rup} / \mathrm{Hi}$ and $\mathrm{kr}$ decrease from 1.18 to 0.86 and from 0.74 to 0.50 and calculated kd increases from 0.68 to 0.87 when $\mathrm{B} / \mathrm{L}$ increases from 0.045 to 0.55 . In addition, the figure shows that, a reasonable agreement is obtained between the calculated and the measured hydrodynamic coefficients. 

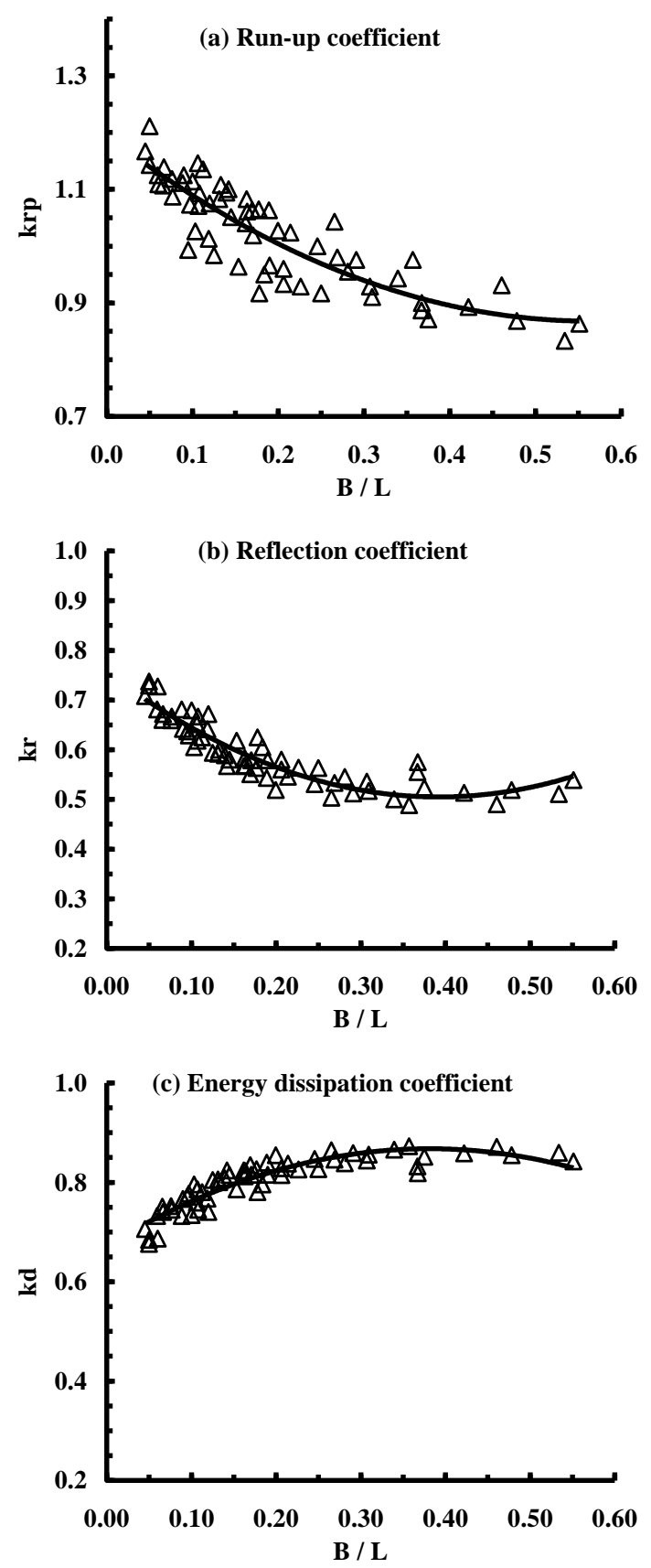

Fig. 12. Effect of $B / L$ on the different hydrodynamic coefficients.

\section{CONCLUSIONS}

The efficiency of a new type seawall, which consists of front screen wall (steel screen suspended on nearly spaced piles), back solid wall and crushed stone filled in between the two walls. The wave run-up, reflection, and energy dissipation characteristics are studied for regular waves of different wave heights and periods. The salient conclusions are given below.

1- In general, the run-up and reflection coefficients decreases with relative wave length $(\mathrm{h} / \mathrm{L})$, wave steepness $\left(\mathrm{H}_{\mathrm{i}} / \mathrm{L}\right)$, relative seawall width $(\mathrm{B} / \mathrm{L})$ and porous media width $(\mathrm{B} / \mathrm{h})$ increasing while the dissipation coefficient takes the opposite trend.

2- The efficiency of the proposed porous seawall in reducing wave run-up and reflection coefficients is better than the solid type by about 10 to $25 \%$ and 20 to $40 \%$ respectively. Also, it is better than the impermeable one in dissipating the incident wave energy by about 30 to $60 \%$.

3- The increasing of the porous media width, reducing the wave run-up and reflection coefficient and increasing the dissipated wave energy by about 5 to $10 \%, 10$ to $20 \%$ and 5 to $20 \%$ respectively.

4- The empirical equations used for estimating the run-up and reflection coefficients are developed by using the Regression analysis. The results of these equations compared with the experimental results and it give a reasonable efficiency.

\section{REFERENCES}

1- Dalrymple, R. A., Losada, M. A, and Martin, P. A. 1991. "Reflection and transmission from porous structures under oblique wave attack." J. Fluid Mech., 224, 625-644.

2- Dean, R. and Dalrymple R. A., 1984. Wave mechanics for engineering and scientists. Prentice Hall, Inc., Englewood, Cliffs, New Jersey.

3- Hsu, H. J., Huang, L. H. and Hsieh, P. C., 2005. Oblique impact of water waves on thin porous walls. J. of Eng. Mechanics, 131 (7), 721-732.

4- Huang, L. H. and Chao, H. I., 1992. Reflection and transmission of water wave by porous breakwater. J. Waterway, Port, Coastal, and Ocean Eng., 118 (5), 437-452.

5- Isaacson, M., Baldwin, J., Allyn, N. and Cowdell, S. 2000. Wave interactions with perforated breakwater. J. Waterway, Port, Coastal, and Ocean Eng., 126(5), 229-235.

6- Lean, G. H.,1967. A simplified theory of permeable wave absorbers. J. of Hydraulic Research, 5 (1), 15-30. 
7- Lin, P and Karunarathna, S. A. S. A. 2007. Numerical study of solitary wave interaction with porous breakwaters. J. of Waterway, Port, Coastal, and Ocean Eng., 133 (5), 352-363.

8- Liu, P. L. F., Lin, P., Chang, K. A., and Sakakiyama, T., 1999. Numerical modeling of wave interaction with porous structures. J. of Waterway, Port, Coastal, Ocean Eng., 125 (6), 322-330.

9- Losada, I. J., Losada, M. A., and Baquerizo, A., 1993. An analytical method to evaluate the efficiency of porous screens as wave dampers. Applied Ocean Research 15, 207-215.

10- Madsen, O. S., 1974. Wave transmission through porous structures. J. of Waterway, Harbor and Coastal Eng. Division, 100 (3), 169-188.

11- Madsen, P. A., 1983. 'Wave reflection from a vertical permeable wave absorber.' Coastal Eng. 7, 381-396.

12- Mallayachari, V. and Sundar, V. 1994. Reflection characteristics of permeable seawalls. Coastal Engineering 23 (1994) 135-150

13- Rageh, O. S., 2009. Hydrodynamic efficiency of vertical thick porous breakwaters. $13^{\text {th }}$ International Water Technology Conference, IWTC 13 2009, Hurghada, Egypt
14- Requejo, S., Vidal, C., Losada, I. J., 2002. Modeling of wave loads and hydraulic performance of vertical permeable structures. Coastal Eng. 46, 249-276.

15- Sollitt, C. K., and Cross, R. H., 1972. Wave transmission through permeable breakwaters. Proceeding of $13^{\text {th }}$ International Conference on Coastal Engineering, ASCE, New York, 18271846.

16- Straub, L. G., Bowers, C. E. and Herbich, J. B., 1957. Laboratory studies of permeable wave absorbers. In: Proc. of $6^{\text {th }}$ Conf. Coastal Eng., Gainesville/Palm Beach/Miami Beach, FL, Tech Paper 18, Series A, 729-742.

17- Sulisz, W., 1985. Wave reflection and transmission at permeable breakwaters of arbitrary cross-section. Coastal. Eng. 9, 371-386.

18- Theocharis, I., Anastasaki, E. N., Moutzouris, C. I. and Giantsi, T., 2011. A new wave absorbing quay-wall for wave height reduction in a harbor basin. Ocean Engineering 38, 1967-1978.

19- Twu, S. W., and Liu, C. C., 2004. Interaction of non-breaking regular waves with a periodic array of artificial porous bars. Coastal Eng. 51, 223-236.

20- Yu, X., 1995. Diffraction of water waves by porous breakwaters. J. Waterway, Port, Coastal, Ocean Eng., 121 (6), 275-282. 